\title{
Article \\ Public Investment on Irrigation and Poverty Alleviation in Rural Laos
}

\author{
Bounmy Inthakesone *(D) and Pakaiphone Syphoxay
}

check for updates

Citation: Inthakesone, Bounmy, and Pakaiphone Syphoxay. 2021. Public Investment on Irrigation and Poverty Alleviation in Rural Laos. Journal of Risk and Financial Management 14: 352. https://doi.org/10.3390/jrfm14080352

Academic Editors: Stephen Polasky, Rakesh Gupta and Tarlok Singh

Received: 4 June 2021

Accepted: 16 July 2021

Published: 2 August 2021

Publisher's Note: MDPI stays neutral with regard to jurisdictional claims in published maps and institutional affiliations.

Copyright: (c) 2021 by the authors. Licensee MDPI, Basel, Switzerland. This article is an open access article distributed under the terms and conditions of the Creative Commons Attribution (CC BY) license (https:/ creativecommons.org/licenses/by/ $4.0 /)$.
Faculty of Economics and Business Management, National University of Laos, Vientiane P.O. Box 7322, Laos; syphoxay1881@gmail.com

* Correspondence: b.inthakesone@nuol.edu.la

\begin{abstract}
The demand for water is rising rapidly, particularly in agricultural and environmental sectors. This has led to more competition to access limited and scarce water resources. Therefore, choosing an appropriate approach to manage water resources, distribution and allocation, to attain sustainable agriculture is critical for every country worldwide. The most well-known method to preserve or store water and adaptation strategy to climate change is irrigation. This paper wished to understand the impact of irrigation on farmers' income in Laos, especially from rice, which is the main crop of rural people. The difference in differences (DID) method was employed to estimate the regression results. The DID was estimated by the pooled OLS of the effect on the log of households' rice farm income and log of households' total income with household head's age, education, gender, household size, ethnicity and harvest areas variables pointing out the coefficients of the outcome variables of interest (after treatment) were 0.037 and 0.076 with positive sign but statistically insignificant. The result implies irrigation has no impact on rice products. In other words, irrigation does not increase households' income. The finding indicates the type of irrigation, the location of the operation headquarters and the management system or governance are crucial factors for explaining the impact of irrigation on the rice products in Laos.
\end{abstract}

Keywords: public investment; irrigation; rice productions; total income; panel data; difference in differences

\section{Introduction}

The demand for water continues to rise rapidly, particularly in agricultural and environmental sectors, thus creating more competition to gain access to the limited and scarce water resources. Therefore, choosing an appropriate approach to manage water resources, distribution and allocation, to attain sustainable agriculture is critical for every country worldwide. The most well-known procedure to preserve or store water is irrigation, which is also one of the prime factors for agricultural development. Irrigation is the single most important component for sustainable agricultural production as it improves agricultural production and ensure food security, which reduce poverty (Nonvide 2018b). Consequently, development of irrigation is vital for a country in which the majority of the population depends on agricultural production. According to Food and Agriculture Organization (FAO 2018), the Asian region like China, India, Indonesia, Bangladesh, Vietnam, Thailand, Myanmar and the Philippines are well-known as rice producer and consumer in the world, accounting for $90.8 \%$ of Asian production.

Agriculture plays a dominant role in the Lao economy since it contributes to about $60 \%$ of gross domestic products and employment of $85 \%$ of the workforce, especially rural people (Bourdet 2000). Access to reliable irrigation can help farmers to adopt new technologies and intensify cultivation, which can lead to increase in productivity and overall higher production. This, in turn, can open doors for new employment opportunities both on-farm and off-farm as well as lead to an increase in household incomes and better quality of life in rural areas. Overall, irrigation has a significant income-generating function 
in agriculture specifically. The government of Laos had realized without an essential irrigation infrastructure, it would have been impossible to bring the country out of poverty in 2015 and break away from the least-developed country status by 2020. For this reason, there is heavy public investment in basic infrastructures, particularly irrigation, nationwide.

To ensure an increase in productivity in sectors of agriculture, animal rearing, fish raising, tree growing and others, inclusive of food provision and commercialized production, a strong infrastructure, electricity network and irrigation system are required to guarantee success. Thus, the process of irrigation is considered a national urgent task because water is vital for life and production. The process by which water is utilized to increase agriculture production is known as irrigation. Improving agriculture and enhancing as a result of irrigation could lead to income generation and poverty alleviation (Nakawuka et al. 2018; Van Rooyen et al. 2017).

In terms of economy, poverty occurs when an individual's income is insufficient to support their standard of living or when their income is below that required for sustenance in society. The definition of poverty is based on disposable income and the factor used to assess poverty is household income or expense. Furthermore, to solve this issue, the focus should be on improving the household income by increasing the efficiency of utilization of production components, production processes and services. Improvement in the market condition can help provide facilities to those needing them, including support in various forms, such as allowance and others. The concept of poverty can be understood using two different approaches: the first, "absolute poverty" that assesses the basic needs of a household to survive, which can also be translated into money known as "poverty line" that is compared with the household income and, second, "relative line" that compares a household's standard of living with the average standard, i.e., "income inequality" Chen and Ravallion (2001).

Agriculture is a source of food and virtually a primary resource for living in every country in the world, particularly for developing countries, where the population growth rate stands at $3 \%$ annually. At this rate, the population figure will double in 25 years. When the population growth rate increases, so does the demand for food supply. Additionally, agriculture can be considered as a capital saving, indicating an agriculturally self-sufficient country can import lesser products-thus, the national saving is expected to be highresulting in the possession of a large pool of capital to promote industrial and service sector, etc. At the same time, the agriculture sector is the source of labor for other industries. As reported by the World Bank (2018) that the share of labor force involving in agriculture sector has accounted more than half of total workers in developing country. Several economists such as Lewis (1954) and Fei and Ranis (1961) attempted to understand the role of agriculture labor in industrial development. They believed there existed a large pool of labor or manpower in the agriculture sector that could be moved around to other sectors without affecting itself. In turn, the industry could benefit from cheap labor, thus reducing the production cost and generating higher profit. Further, agriculture is seen as a source of currency because the most exported products of developing countries are mostly agricultural. It also creates a market for industrial products because developing countries need to import industrial equipment and machinery, tools, modernized farm equipment and others to increase production efficiency.

Lao's socio-economic development focuses on agriculture and animal rearing, which are also related to industrial growth and service. Tourism and the country's corridor of power can be used to spearhead investment in building infrastructure and various activities to jump start and speed up the process of economic development sustainably. The objective of socio-economic development is to promote and eradicate poverty and provide the four basic necessities of life: food, clothing, shelter and medicine. To successfully obtain these necessities, household residents need to be allowed to live their life to the fullest and be involved in the community, thus getting the chance to participate in socioeconomic, cultural and political activities and becoming a part of the economic mainstream. What follows is the effect on their life and country. There is a need to focus on food 
production, strengthening the production foundation, encouraging a more systematic way of animal rearing, providing seedling and baby animals, information, disseminating information, training and working on scientific technique to increase the efficacy and sustainability to boost food production to meet the demand by advocating the growth of high-protein plants, vegetables, fruit trees and industrial plants, thus advancing the animal rearing commercialization. Moreover, a special financial preference needs to be given to this sector, including long-term and low-rate loan for investment, to establish a secure foundation for food production and the emphasis should be on commercialization, which needs to be in line with the eradication of shifting cultivation and provision of permanent employment to the farm population. Thus, the State and the party have urged for commercialization to gradually increase individual household income to deal with poverty. The focus is on agricultural products to substitute imported goods-to make them available for consumption and sold locally in the market. There is also emphasis on producing goods to be consumed domestically, particularly the commercialization of industrial unit and crafts to reduce the import goods and to generate more employment for the minority population, resulting in the gradual improvement in their standard of living.

Rice is a main staple food crop that has experienced rapid growth in the past two decades and the country has been transformed from an importer to an exporter (Welcher and Prasertsri 2019). Nonvide (2017) tested the impact of irrigation on rice productivity in Benin by applying the Heckman selection model and found that irrigated households can improve rice productivity by approximately 57\% compared to their non-irrigated counterparts. Moreover, Bidzakin et al. (2018) suggests that irrigation utilization should be intensely promoted to rice farmers to increase rice productivity and profits. Nguyen et al. (2017) indicated that irrigation increases the land area for rice, corn and potato in Vietnam.

Madhusudan and Narayanamoorthy (2003) examined the impact of irrigation on the reduction of rural poverty in India. The studied panel data was applied from the year 1970 to 1993 in 14 different states of India. The result revealed the construction of an irrigation system has no effect on the alleviation of poverty. A majority of farmers are using fertilizer for production in areas without irrigation water; besides, more rainwater has been commonly used in lieu of that from irrigation. Hussain and Hanjra (2003) carried out a similar study to examine the effect of irrigation on the reduction of poverty in South Asia and South-East Asia. The study included India (1996), Vietnam (1996), Philippines (1997), Thailand (1998), Sri Lanka (2000) and Pakistan (2000) and was in the form of descriptive analysis, which suggested household using irrigation water can increase production; additionally, its production volume can increase significantly than that of a household using no irrigation water. Thus, this is considered as one of the factors contributing to alleviating poverty.

Michael et al. (2003) examined the effect of irrigation on the alleviation of poverty in India. They conducted descriptive and qualitative analysis to understand the effect of irrigation on the environment due to building a dam. The results of their study contributed to the economic growth, which was insignificant compared to that of the irrigation in the 1970's. The study indicated the irrigation system presents a vital component in the agriculture production in a major effort to alleviate poverty. Huang et al. (2002) examined the impact of irrigation on income, poverty and distribution of income in rural regions by using the information gathered in rural areas in 2000. They used descriptive analysis to explain the relationship between irrigation and income and irrigation and poverty. The term "decomposed" to denote the source of income and the people with and without access to irrigation included in the study on the effect of irrigation on income distribution and inequality. The study demonstrated irrigation had a direct impact on income and poverty and contributed to redressing inequality as well.

Bose et al. (2007) assessed the effect of the outcome of government expenditure on the economic growth of some 30 developing countries between the period of 1970-1980 using the "endogeneity test" and three-stage least squares (3SLS). Although the study hinted at some significant difference in government expenditure between developed and 
developing countries, result of the study, in contrast, revealed the government expenditure on transportation, communication and defense was insignificant compared to that on education regarding the long-term economic growth in the developing countries.

This paper sought to answer the question, "what is the impact of infrastructural investments in irrigation on rural household income, which leads to poverty alleviation in rural Laos?" and, more precisely, "what are the mechanisms that can be used to influence rural household income?" The findings of this study can contribute to evaluating the impact of infrastructure investments, particularly irrigation, on poverty alleviation by bringing in new empirical evidence and can be used as a source of information for policymakers in making an appropriate policy for poverty eradication in the future.

\section{Objective}

This paper seeks to estimate the impact of investment in irrigation infrastructure on the outcome variables, which is considered a vital variable in influencing rural household income. The specific objectives of this paper are as follows:

To understand the impact of investment in irrigation infrastructure on rice farm income and the total income on the household level.

To study the effect of cultivated areas, age, gender, education, household size, household with tractor and fertilizer and household with access to electricity and financial resources on rice farm income and the total income on the household level.

\section{Method and Materials}

\subsection{Data}

This paper utilized data from Lao Statistic Bureau (LSB), particularly the Lao Expenditure and Consumption Survey (LECS), the largest and most comprehensive survey in Laos, which does not only cover a large sample size but also a wide range of subject matter areas related to household living situation, consumption, income, self-production in agriculture and household-related business, construction, access to services, social indicators and food or rice intake. Five LECS were carried out starting from 1992/1993. For the purpose of this study, only LECS 3 (Lao Statistic Center of Laos 2003) and LECS 4 (Lao Statistic Center of Laos 2008) were utilized, since LECS 1 and LECS 2 are not in line with this study. A total of 540 villages and 518 villages in LECS 3 and LECS 4, respectively, were included in the analysis.

At the village level, 506 villages matched both LECS and 441 villages without the irrigation scheme in LECS 3 matched with that in LECS 4. As a result, 91 villages with an irrigation scheme were considered treatment groups and the remaining 350 villages comparison groups.

\subsection{Theoretical Model}

The present study used a suitable comparator, which is defined as the comparison of various outcomes before and after the irrigation project, a comparison with or without projects. It borrowed from the works of Lokshin and Yemtsov (2005). The outcome measure $Y_{i}$ for a project in an $i$ th individual household is defined as

$$
Y_{i t}=Y_{i t}^{*}+G_{i t}{ }^{I} D_{i}
$$

where $\mathrm{Y}_{\mathrm{i}}^{*}$ is the outcome for an individual household if the project is not implemented and $\mathrm{Gi}^{\mathrm{I}}$ the gain individual household $i$ from an outcome attributable to a project. Then, the estimate of the average impact of the project on a treatment group, dummy variable $D_{i}=1$, can be given by

$$
\mathrm{E}\left(\mathrm{Y}_{\mathrm{it}} \mid \mathrm{D}_{\mathrm{i}}=1\right)-\mathrm{E}\left(\mathrm{Y}_{\mathrm{it}} \mid \mathrm{D}_{\mathrm{i}}=0\right) \equiv \mathrm{E}\left(\mathrm{Y}_{\mathrm{it}}{ }^{*} \mid \mathrm{D}_{\mathrm{i}}=1\right)+\mathrm{E}\left(\mathrm{G}_{\mathrm{it}}{ }^{\mathrm{I}} \mid \mathrm{D}_{\mathrm{i}}=0\right)-\mathrm{E}\left(\mathrm{Y}_{\mathrm{it}}{ }^{*} \mid \mathrm{D}_{\mathrm{i}}=0\right)
$$


A simple comparison of the means between the treatment and control group shows there is no biased estimation if $\mathrm{E}\left(\mathrm{Y}_{\mathrm{i}}^{*} \mid \mathrm{D}_{\mathrm{i}}=1\right)-\mathrm{E}\left(\mathrm{Y}_{\mathrm{i}}^{*} \mid \mathrm{D}_{\mathrm{i}}=0\right)$, part in Equation (2) is equal, or

$$
\begin{gathered}
\mathrm{E}\left(\mathrm{Y}_{\mathrm{it}}{ }^{*} \mid \mathrm{D}_{\mathrm{i}}=1\right)-\mathrm{E}\left(\mathrm{Y}_{\mathrm{it}}^{*} \mid \mathrm{D}_{\mathrm{i}}=0\right)=0 \\
\mathrm{E}\left(\mathrm{Y}_{\mathrm{it}}{ }^{*} \mid \mathrm{D}_{\mathrm{i}}=1\right)=\mathrm{E}\left(\mathrm{Y}_{\mathrm{it}}{ }^{*} \mid \mathrm{D}_{\mathrm{i}}=0\right)
\end{gathered}
$$

However, some unobserved characteristics of an individual household or village correlated to project outcome may also be correlated to project placement. The underlying assumption is the time trend in the control is an adequate proxy for the time trend occurring in the treatment group in the absence of the project.

The DID method assumes the following condition on a set of observed characteristics $\mathrm{X}$ as,

$$
\mathrm{E}\left(\mathrm{Y}_{\mathrm{i} 1}{ }^{*}-\mathrm{Y}_{\mathrm{i} 0}{ }^{*} \mid \mathrm{D}_{\mathrm{i}}=1, \mathrm{X}\right)=\mathrm{E}\left(\mathrm{Y}_{\mathrm{i} 1}{ }^{*}-\mathrm{Y}_{\mathrm{i} 0}{ }^{*} \mid \mathrm{D}_{\mathrm{i}}=0, \mathrm{X}\right)
$$

The mean DID for the outcome is estimated by taking the expectation of Equation (1) and the overall $\mathrm{N}$ sample villages using Equation (5), which is defined as,

$$
\left.\mathrm{E}\left[\left(\mathrm{Y}_{\mathrm{i} 1}^{*}-\mathrm{Y}_{\mathrm{i} 1}^{*}\right)-\left(\mathrm{Y}_{\mathrm{i} 0^{*}}-\mathrm{Y}_{\mathrm{i} 0^{*}}\right) \mid \mathrm{D}_{\mathrm{i}}=1\right)\right]=\mathrm{E}\left[\left(\mathrm{G}_{\mathrm{i} 1}{ }^{\mathrm{I}} \mathrm{D}_{\mathrm{i}}=1\right)\right.
$$

If the outcomes in period (0) are not found to be correlated with project placement, then the result of Equation (6) indicates the mean has changed in the outcome of the treatment group.

Another bias that these methods cannot remove is the time variant's unobservable characteristics are correlated with both project placement and the outcomes of the intervention. In particular, project placement could be based on unobserved community characteristics correlated with changes in the expected project outcomes. However, this bias may not arise in the context of micro-projects in rural areas. Thus, placement can reduce (but not completely eliminate) the possible bias of the time-variant.

\subsection{Empirical Model}

This study tried to use a suitable comparator, which is defined as a comparison of various outcomes before and after irrigation project, a comparison with or without projects. The DID method was used in this analysis and the main assumption for this method is, without intervention, the change in values of the outcomes between treatment and control groups should be comparable. The DID in econometric model is presented below:

$$
Y_{\text {it }}=\beta_{0}+\beta_{1} \text { after }_{\mathrm{t}}+\beta_{2} \text { treat }_{\mathrm{i}}+\delta_{1} \text { treat }_{\mathrm{i}} \times \text { after }_{\mathrm{t}}+\beta_{3} X_{i t}+u_{i t}
$$

$\mathrm{Y}_{\mathrm{it}}$ indicates the outcome of interest, such as rice farm income, non-farm income and total income, total, of household $i$ in year $t$;

After $=1$ after treatment (2003) and 0 before treatment (2008);

Treat $=1$ if in the treatment group and 0 if in the control group;

$X_{i t}$ is a vector that can capture household and village characteristics that affect a household's decision to access irrigation, such as household head's age, education and gender, household size, ethnicity and harvest areas. These variables were used in the studied of Khor and Feike (2017), Bidzakin et al. (2018), Nonvide (2018a)

$u_{i t}$ is an error that represents unobserved factors that affect $Y_{i t}$.

The coefficient of interest is on the interaction term, $\delta_{1}$. This gives us the DID estimator of the treatment effect.

\section{Results and Discussion}

\subsection{Descriptive Statistics}

The descriptive statistics of the data are presented in Table 1 . The minimum household rice farm income in the sample size is 130,000 Kip and the maximum 90,000,000 Kip (Kip is Lao local currency, \$US $1=8200 \mathrm{Kip}, \mathrm{BCEL}$ exchange rate, 28 December 2016). The mean 
and standard deviation of household rice farm income were found to be 4,283,088 and $5,125,782$, respectively. The minimum household total income was found to be $195,000 \mathrm{Kip}$ and the maximum 91,000,000 Kip. The mean and standard deviation of household rice farm income were found to be 5,281,843 and 5,934,635, respectively. The minimum household cultivated area was $0.02 \mathrm{ha}$ and the maximum $12 \mathrm{ha}$. The mean and standard deviation of household cultivated areas were found as 1.463 and 1.171, respectively. The minimum age of the head of the household was 17 years old and the maximum 86 years old. The mean and standard deviation of household rice farm income were 44.789 and 11.500 , respectively. The minimum number of years of education of the head of the household was found to be 0 (no education) and the maximum 18 years (undergraduate degree). The mean and standard deviation of the number of years of education of the head of the household were13.5 and 3.375 , respectively. The minimum family size was 1 person and the maximum 20 people. The mean and standard deviation of family size were 6.176 and 2.302, respectively. Other variables were treated as dummy variables, such as household with tractors and fertilizers for their farms and households with electricity access to financial sources (presented in Table 2 below).

Table 1. Sample size.

\begin{tabular}{ccccc}
\hline \multirow{2}{*}{ Item } & \multicolumn{2}{c}{ Treatment Groups } & \multicolumn{2}{c}{ Control Groups } \\
\cline { 2 - 5 } & No. of Villages & No. of Households & No. of Villages & No. of Households \\
\hline LECS 3 & 91 & 500 & 350 & 1494 \\
LECS 4 & 91 & 235 & 350 & 766 \\
Total & 182 & 735 & 700 & 2260 \\
\hline
\end{tabular}

Source: Authors' computations (2016).

Table 2. Descriptive statistics of the variables used in the DID regression analysis.

\begin{tabular}{ccccc}
\hline Variable & Minimum & Maximum & Mean & Std. Deviation \\
\hline After (dummy) & 0 & 1 & 0.338 & 0.473 \\
Treatment (dummy) & 0 & 1 & 0.250 & 0.433 \\
Aftertreatment (dummy) & 0 & 1 & 0.084 & 0.277 \\
Rice farm income (Kip) & 130,000 & $90,000,000$ & $4,283,088$ & $5,125,782$ \\
Total income (Kip) & 195,000 & $91,000,000$ & $5,281,843$ & $5,934,635$ \\
Cultivated areas (ha) & 0.02 & 12 & 1.463 & 1.171 \\
Age (head of HH) & 17 & 86 & 44.789 & 11.500 \\
Gender (head of HH, dummy) & 0 & 1 & 0.959 & 0.199 \\
Year of Education (head of HH) & 0 & 18 & 13.500 & 3.375 \\
Family Size (persons) & 1 & 20 & 6.176 & 2.302 \\
Tractor (dummy) & 0 & 1 & 0.290 & 0.454 \\
Fertilizer (dummy) & 0 & 1 & 0.344 & 0.475 \\
Electric (dummy) & 0 & 1 & 0.520 & 0.500 \\
Financial (dummy) & 0 & 1 & 0.068 & 0.252 \\
Number of Observations & 3013 & & & \\
\hline
\end{tabular}

Source: Author's calculation.

\subsection{Results of the DID Estimation on the Household Level}

The DID methodology was used to obtain all results in this section. Equation (7) was used to confirm the DID method met its main assumption mentioned in the methodology part. This section begins with the baseline of irrigation project survey in 2003.

Table 3 shows the mean of the outcome variables in the baseline survey (2003) for a group of villages with an irrigation project (treatment group) and a group of villages without an irrigation project (control group). All the outcome variables in the treatment group and the control group are slightly different. However, they are not statistically significant, with the exception of the number of households using tractor and number of households using fertilizer. This indicates that in general, there is no statistically significant difference in the mean of outcome variables between the treatment and the control group in the baseline survey and that without the intervention of irrigation project, the mean of the 
outcome variables in both the groups is comparable, which supports the main assumption of the DID method.

Table 3. Comparison of the mean of some of the variables in the baseline survey (2003).

\begin{tabular}{ccc}
\hline Outcome Variables & Treatment Group & Control Group \\
\hline Expenditure (KIP) & $1,563,000$ & $1,633,050$ \\
Total production (ton) & 3415.79 & 3708.23 \\
Productivity (ton/ha) & 3152.20 & 3521.37 \\
Rice farm income & 14.646 & 14.544 \\
Total income & 14.916 & 14.826 \\
Cultivated areas (ha) & 1.64 & 1.32 \\
HH using tractor & 0.31 & $0.22 * * *$ \\
HH using fertilizer & 0.36 & $0.29^{* * *}$ \\
\hline
\end{tabular}

Source: Reproduced by the Author; ${ }^{* * *}$ represents significance level at 1.

Table 4 shows the results of the DID of the impact of irrigation on log rice farm income using simple calculation. The result indicates that the coefficient of interest is 0.019 with a positive sign but statistically insignificant. It also illustrates that household with access to irrigation may not have any impact on rice farm income. In other words, there is no difference in the farm income between households with and without access to irrigation. This result is inconsistent with the initial purpose of investment in irrigation infrastructure. In other words, the investment in irrigation in Laos is insignificant.

Table 4. The DID estimation of the impact of irrigation on log rice farm income.

\begin{tabular}{cccc}
\hline & Treatment Group & Control Group & Difference \\
\hline Before & 14.646 & 14.544 & 0.101 \\
After & 15.455 & 15.335 & 0.12 \\
\hline Difference & -0.809 & -0.791 & 0.019 \\
& & & $(0.076)$ \\
\hline No. of obs. & 3013 & 3013 & 3013 \\
\hline
\end{tabular}

Note: before $=2003$; after $=2008$ and the within the parenthesis is standard error.

The result mentioned above was obtained from simple statistics and calculation. To confirm this result, the author applied the econometric technique like the DID. Table 5 presents the result of the DID estimated by pooled OLS without and with control variables, which shows the value of the outcome variable of interest (aftertreatment variable) is 0.019 and 0.037 in both the cases. However, this value is statistically insignificant. These estimation outcomes support the result obtained using DID, demonstrated above and imply the irrigation has no impact on rice farm income. In other words, irrigation does not lead to an increase in rice products as per government expectation, since the price in the period of the study does not change by much.

Interestingly, the DID results estimated by pooled OLS with control variables show that cultivated areas, family size, households using tractors and fertilizers and households with electricity and access to financial sources have a positive sign and are statistically significant at the $1 \%$ level. The cultivated areas variable has a coefficient value of 0.399 with positive sign and statistically significant at the $1 \%$ level. This empirical result illustrates an increase in cultivated areas with 1 ha households may lead to an increase in rice farm income by around $39.9 \%$. The family size variable indicates the same result; the coefficient value of this variable is 0.03 with a positive sign and statistically significant at the $1 \%$ level. The result implies that households with additional labor may lead to increase in rice farm income by around 3\%. 
Table 5. The DID estimated by pooling the OLS of the impact of irrigation on log rice farm income with and without control variables.

\begin{tabular}{|c|c|c|c|c|}
\hline \multirow{2}{*}{ Independent Variable } & Single & \multirow{2}{*}{ SE } & Multiple & \multirow{2}{*}{ SE } \\
\hline & Pooled OLS & & Pooled OLS & \\
\hline After (dummy) & 0.791 & 0.038 & $0.722 * * *$ & 0.035 \\
\hline Treatment (dummy) & 0.101 & 0.044 & 0.034 & 0.036 \\
\hline Aftertreatment (dummy) & 0.019 & 0.076 & 0.037 & 0.058 \\
\hline Cultivated areas (ha) & - & - & $0.399 * * *$ & 0.015 \\
\hline Age (head of $\mathrm{HH})$ & - & - & 0.001 & 0.001 \\
\hline Gender (head of $\mathrm{HH}$, dummy) & - & - & -0.017 & 0.061 \\
\hline Year of Education (head of $\mathrm{HH}$ ) & - & - & 0.007 & 0.014 \\
\hline Family Size (persons) & - & - & $0.030^{* * *}$ & 0.005 \\
\hline Tractor (dummy) & - & - & $0.298^{* * *}$ & 0.028 \\
\hline Fertilizer (dummy) & - & - & $0.119^{* * *}$ & 0.027 \\
\hline Electric (dummy) & - & - & $0.100^{* * *}$ & 0.027 \\
\hline Financial (dummy) & - & - & $0.224^{* * *}$ & 0.060 \\
\hline Constant & 14.544 & 0.022 & $13.569 * * *$ & 0.087 \\
\hline Number of Observations & & 3013 & & 3013 \\
\hline R-squared & & 0.163 & & 0.521 \\
\hline Adjusted R-squared & & 0.162 & & 0.519 \\
\hline Prof $>F$ & & 0.000 & & 0.000 \\
\hline
\end{tabular}

Note: before $=2003$; after $=2008 ;{ }^{* * *}$ represents significance level at $1 \%$.

For the dummy variables, the coefficient value of households using tractors for their farm is 0.289 with a positive sign and statistically significant at the $1 \%$ level. The result suggests households using tractors for their farm can increase their rice farm income more than those without tractors by about $28.9 \%$. The coefficient value of households using fertilizers for their farm is 0.119 with a positive sign and statistically significant at the $1 \%$ level. The result suggests households using fertilizers for their farm can increase their rice farm income more than those without fertilizers by about $11.9 \%$. The coefficient value of households with electricity is 0.1 with a positive sign and statistically significant at the $1 \%$ level. The result implies that households with electricity can increase their rice farm income more than those without electricity by about $10 \%$. The last dummy variable is access to finance. The coefficient value of households with access to financial sources is 0.224 with a positive sign and statistically significant at the $1 \%$ level. The result indicates households with access to financial sources can increase their rice farm income more than those without access by about $22.4 \%$. Control variables such as the age of the head of the household, gender of the head of the household and the number of years of education of the head of the household are statistically insignificant.

Table 6 shows the results of DID of the impact of irrigation on log total income using simple calculation. The result indicates the coefficient of interest is 0.034 with a positive sign but statistically insignificant. It also illustrates households with access to irrigation may not have any impact on their total income. In other words, there is no difference in the total income between households with and without access to irrigation. This result is inconsistent with the initial purpose of investment in irrigation infrastructure. In other words, investment in irrigation in Laos is insignificant.

Table 6. The DID estimation of the impact of irrigation on log total income.

\begin{tabular}{cccc}
\hline & Treatment Group & Control Group & Difference \\
\hline Before & 14.916 & 14.826 & 0.090 \\
After & 15.668 & 15.545 & 0.123 \\
\hline Difference & -0.752 & -0.719 & 0.034 \\
& & & $(0.071)$ \\
\hline No. of obs. & 3013 & 3013 & 3013 \\
\hline
\end{tabular}

Note: before $=2003$; after $=2008$ and within the parenthesis is standard error. 
Here, the variable outcome of interest is the household's total income, as presented in Table 7. The result of the DID estimated by pooled OLS with and without household head's age, education and gender, household size, ethnicity and harvest areas variables showed the values of the outcome variable of interest (aftertreatment variable) are 0.033 and 0.076 in both the cases. However, these values are statistically insignificant. This supports the result obtained using the DID, determined above and implies irrigation has no impact on the household's total income. In other words, irrigation does not lead to the increase in farm products as per government expectation, since the price in the period of the study does not change by much.

Table 7. The DID estimated by single and multiple pooled OLS of the effect on log total income.

\begin{tabular}{|c|c|c|c|c|}
\hline \multirow{2}{*}{ Independent Variable } & Single & \multirow{2}{*}{ SE } & Multiple & \multirow{2}{*}{ SE } \\
\hline & Pooled OLS & & Pooled OLS & \\
\hline After (dummy) & $0.718^{* * *}$ & 0.035 & $0.698^{* * *}$ & 0.033 \\
\hline Treatment (dummy) & $0.089 * *$ & 0.041 & 0.0003 & 0.032 \\
\hline Aftertreatment (dummy) & 0.033 & 0.071 & 0.076 & 0.052 \\
\hline Cultivated areas (ha) & - & - & $0.334^{* * *}$ & 0.012 \\
\hline Age (head of $\mathrm{HH})$ & - & - & 0.007 & 0.001 \\
\hline Gender (head of $\mathrm{HH}$, dummy) & - & - & -0.082 & 0.059 \\
\hline Year of Education (head of $\mathrm{HH}$ ) & - & - & 0.051 & 0.013 \\
\hline Family Size (persons) & - & - & $0.029^{* * *}$ & 0.004 \\
\hline Tractor (dummy) & - & - & $0.319^{* * *}$ & 0.026 \\
\hline Fertilizer (dummy) & - & - & $0.167^{* * *}$ & 0.025 \\
\hline Electric (dummy) & - & - & $0.110^{* * *}$ & 0.025 \\
\hline Financial (dummy) & - & - & $0.279^{* * *}$ & 0.056 \\
\hline Constant & $14.825^{* * *}$ & 0.020 & $13.910 * * *$ & 0.084 \\
\hline Number of Observations & & 3013 & & 3013 \\
\hline R-squared & & 0.158 & & 0.501 \\
\hline Adjusted R-squared & & 0.157 & & 0.544 \\
\hline Prof $>F$ & & 0.000 & & 0.000 \\
\hline
\end{tabular}

Interestingly, the DID results estimated by pooled OLS with household head's age, education and gender, household size, ethnicity and harvest areas variables show that cultivated areas, family size, households using tractors and fertilizers and households with electricity and access to financial sources have a positive sign and are statistically significant at the $1 \%$ level. The cultivated areas variable show that the coefficient value is 0.334 with a positive sign and statistically significant at the $1 \%$ level. This empirical result illustrates that an increase in cultivated areas with 1 ha households can lead to an increase in the rice farm income by around $33.4 \%$. The family size variable indicates the same result; the coefficient value of this variable is 0.029 with a positive sign and statistically significant at the $1 \%$ level. The result implies that households with additional labor may increase their rice farm income by around $2.9 \%$.

For the dummy variables, the coefficient value of households using tractors for their farm is 0.319 with a positive sign and statistically significant at the $1 \%$ level. The result suggests households using tractors for their farm can increase their rice farm income more than those without tractors by about $31.9 \%$. The coefficient value of households using fertilizers for their farm is 0.167 with a positive sign and statistically significant at the $1 \%$ level. The result suggests that households using fertilizers for their farm can increase their rice farm income more than without fertilizers by about $16.7 \%$. The coefficient value of households with electricity is 0.11 with a positive sign and statistically significant at the $1 \%$ level. The result implies that households with electricity can increase their rice farm income more than those without electricity by about $11 \%$. The last dummy variable is access to finance. The coefficient value of households with access to financial sources is 0.279 with a positive sign and statistically significant at the $1 \%$ level. The result indicates that households with access to financial sources can increase their rice farm income higher 
than those without access by about $27.9 \%$. Other control variables such as the age of the head of the household, the gender of the head of the household and the number of years of education of the head of the household are statistically insignificant.

\subsection{Discussion}

The results obtained from the estimation from pooled OLS with household head's age, education and gender, household size, ethnicity and harvest areas variables show a positive sign but are statistically insignificant for the outcome variables of interest, such as the household rice farm income and total income. However, the DID estimated by pooled OLS of the impact of irrigation on the log of the household rice farm income and total income with household head's age, education and gender, household size, ethnicity and harvest areas variables show the coefficient of interest (treatment) is 0.037 and 0.076 with a positive sign but statistically insignificant, respectively. The result implies irrigation has no impact on rice products or does not increase rice products based on our expectation. This is contrast with Sengsourivong and Ichihashi (2019) that the average sales value and total production of sticky rice for irrigated households is greater than those for non-irrigated households by around 36 to $38 \%$ per season. The result is somewhat strange because household income or the income of rural people, especially in a country like Laos, comes predominantly from rice products and about $90 \%$ of Lao agriculture dominates in rice (Bourdet 2000). There are two possible explanations for this phenomenon: first, the inaccuracy of the data. For this reason, this paper utilized the data from LECS 3 and LECS 4. The data set provides information only about villages with or without irrigation system (not household level) but does not provide accurate information on, for instance, the types of irrigation and the location of operation headquarters. Further, the data did not give any information about how many households in the village can access the irrigation system. If non-irrigated households have larger households number than their irrigated one, imbalance can be seen in the observed variables and might occur in unobserved variables as well as mentioned by Tran and Goto (2019). Moreover, in LECS 3 and LECS 4, only 15 households were selected as the sample size. These factors are crucial for explaining the impact of irrigation on rice products as well as the household rice farm income and the total income. For example, Laos has five types of irrigation schemes: weir, reservoir, traditional, pump using fuel and pump using electricity (Lao PDR 2008). Each has its own impact on production. Regarding the location of the operation headquarter, Channgakham (2006) found the down-stream zone to have a negative impact on rice production. Households with farmland located in the down-stream of irrigation are most likely to reduce the cultivated area, particularly in the dry season, because of insufficient irrigated water. In contrast, rice cultivation is relatively high in middle-stream or up-stream zones. This can be one explanation in this study.

The other is about management system or government policy, which is related to the management system and site selection problems. Sacklokham (2016) pointed out that due to lack of proper maintenance measures, some irrigation systems cannot be regularly used. Additionally, high electricity costs are another problem and account for $10 \%$ of the crop production cost per hectare, on average. As a result, some farmers do not grow rice in dry reason. This in line with the Irrigation Diagnostic Study of Department of Irrigation, the Ministry of Agriculture and Forestry (Lao PDR 2008) points out that irrigation schemes are not well maintained and organization of water use is extremely weak. Moreover, operational costs such as that of electricity are not paid in full by a majority of users, resulting in large debts, nationally, owed to the electricity department. Scheme infrastructure depreciates rapidly with the lack of maintenance and repair resulting in investment intensive rehabilitation cycles of usually less than 10 years and un-sustainability. In the irrigation management transfer theory, the site selection must be driven by community demand. In the case of Laos, however, it is based on a top-down process pushed by donors or driven by supply, which may create some problems. Furthermore, many site selections are made very close to the city and have no specific 
boundary. As a result, when the population grew, agricultural areas began being used for different purposes.

The above explanations could answer the question of why irrigation has no impact on rice production or no impact on the household rice farm income and total income.

\section{Conclusions}

This paper wished to understand the impact of irrigation on farmers' income, especially the income from rice, which is the main crop for the rural people in Laos. The DID method was employed to estimate the regression results. These results, particularly obtained by the estimation from the DID pooled by OLS with control variables, show the coefficient of the outcome variables of interest (aftertreatment variable) in both the log of the household rice farm income and the log of the household total income are 0.037 and 0.076 with positive sign but statistically insignificant, respectively. The results imply irrigation has no impact on rice production or does not lead to an increase in rice products as per our expectation. In other words, investment in irrigation does not lead to an increase in the household rice farm income and total income. In Laos, the household income or the income of rural people comes predominantly from rice products, which accounts for $90 \%$ of Lao agriculture (Bourdet 2000).

Remarkably, the DID results estimated by pooled OLS with control variables show cultivated areas, family size, households using tractors and fertilizers and households with electricity and with access to financial sources have a positive impact on the household rice farm income and the total income. In other words, an increase in cultivated areas, family size, household using tractors and fertilizers and households with electricity and with access to financial sources can increase the household rice farm income and the total income in general.

These results imply that the government can increase its rural household income and reduce poverty by assigning more land to farmers for more cultivated areas. Further, instead of investing in irrigation, financial support should be given to farmers so that they can afford innovative technology such as tractors and fertilizers. However, there are limitations of this paper: this paper focuses on the household level, but its irrigation project is based on the village level. Moreover, the data itself cannot provide any information related to the type of irrigation, the location of the operation headquarters and the management system. These may be crucial to explain why irrigation has no impact on rice products in the case of Laos.

Author Contributions: B.I. and P.S. contributed evenly. Both authors have read and agreed to the published version of the manuscript.

Funding: This research received no external funding.

Institutional Review Board Statement: Not applicable.

Informed Consent Statement: Informed consent was obtained from all subjects involved in the study.

Conflicts of Interest: The authors declare no conflict of interest.

\section{References}

Bidzakin, John, Simon Fialor, Dadson Awunyo Vitor, and Iddrisu Yahaya. 2018. Impact of Irrigation Ecology on Rice Production Efficiency in Ghana. Advances in Agriculture 2018: 5287138. [CrossRef]

Bose, Niloy, M. Emranul Haque, and Denise Osborn. 2007. Public expenditure and economic growth: A disaggregated analysis for developing countries. The Manchester School 75: 533-56. [CrossRef]

Bourdet, Yves. 2000. The Economics of Transition in Laos: From Socialism to ASEAN Integration. Northampton: Edward Elgar Publishing Ltd. Channgakham, Phinseng. 2006. The effects of a fertilizer loan on dry-season rice cultivated areas in Laos. Economics Bulletin 5: 1-8.

Chen, Shaohua, and Martin Ravallion. 2001. How Did the World's Poorest Fare in the 1990s? Review of Income and Wealth 47: $283-300$. [CrossRef]

FAO. 2018. Food Outlook. Rome: Food and Agriculture Organization (FAO) of the United Nations, pp. 32-37.

Fei, John C. H., and Gustav Ranis. 1961. A Theory of Economic Development. The American Economic Review 51: 533-65. 
Huang, Qiuqiong, Scott Rozelle, Bryan Lohmar, Jikun Huang, and Jinxia Wang. 2002. Irrigation, agricultural performance and poverty reduction in China. Food Policy 31: 30-52. [CrossRef]

Hussain, Intizar, and Munir Ahmad Hanjra. 2003. Does irrigation water matter for rural poverty alleviation? Evidenced from South and South-East Asia. Water Policy 5: 429-42. [CrossRef]

Khor, Ling Yee, and Til Feike. 2017. Economic sustainability of irrigation practices in arid cotton production. Water Resources and Economics 20: 40-52. [CrossRef]

Lao PDR. 2008. Irrigation Diagnostics Study. Vientiane: Department of Irrigation, Ministry of Agriculture and Forestry.

Lao Statistic Center of Laos. 2003. Lao Expenditure and Consumption Survey (LECS 3). Vientiane: Lao Statistic Center of Laos.

Lao Statistic Center of Laos. 2008. Lao Expenditure and Consumption Survey (LECS 4). Vientiane: Lao Statistic Center of Laos.

Lewis, W. Arthur. 1954. Economic Development with Unlimited Supplies of Labor. The Manchester School 22: 139-91. [CrossRef]

Lokshin, Michael, and Ruslan Yemtsov. 2005. Has Rural Infrastructure Rehabilitation in Georgia Helped the Poor? The World Bank Economic Review 19: 311-33. [CrossRef]

Madhusudan, Bhattarai, and A. Narayanamoorthy. 2003. Impact of irrigation on rural poverty in India: An aggregate panel-data analysis. Water Policy 5: 443-58. [CrossRef]

Michael, Lipton, Julie Litchfiel, and Jean Marc Faurès. 2003. The effects of irrigation on poverty: A framework for analysis. Water Policy 5: 413-27. [CrossRef]

Nakawuka, Prossie, Simon Langan, Petra Schmitter, and Jennie Barron. 2018. A review of trends, constraints, and opportunities of smallholder irrigation in East Africa. Global Food Security 17: 196-212. [CrossRef]

Nguyen, Cuong Viet, Tung Duc Phung, Van Khanh Ta, and Dat Tho Tran. 2017. The impact of road and irrigation on household welfare: Evidence from Vietnam. International Review of Applied Economics 31: 734-53. [CrossRef]

Nonvide, Gbetondji Melaine Armel. 2017. Effect of Adopted of Irrigation on Rice Yield in the Municipality of Malanville, Benin. African Development Review 29: 109-20. [CrossRef]

Nonvide, Gbetondji Melaine Armel. 2018a. A re-examination of the impact of irrigation on rice production in Benin: An application of the endogenous switching model. Kasetsart Journal of Social Sciences 40: 657-62. [CrossRef]

Nonvide, Gbetondji Melaine Armel. 2018b. Irrigation adoption: A potential avenue for reducing food insecurity among rice farmers in Benin. Water Resources and Economics 24: 40-52. [CrossRef]

Sacklokham, Silinthone. 2016. Rice-Based Farming System in Lao PDR-Opportunities and Challenges for Food Security. Vientiane: Village Focus International.

Sengsourivong, Bouasone, and Masaru Ichihashi. 2019. Effectiveness of Irrigation Access on Sticky Rice Productivity: Evidence from Lao PDR. Sustainability 11: 5839. [CrossRef]

Tran, Duc, and Daisaku Goto. 2019. Impacts of sustainability certification on farm income: Evidence from small-scale specialty green tea farmers in Vietnam. Food Policy 83: 70-82. [CrossRef]

Van Rooyen, André F., Peter Ramshaw, Martin Moyo, Richard Stirzaker, and Henning Bjornlund. 2017. Theory and application of agricultural innovation platforms for improved irrigation scheme management in Southern Africa. International Journal of Water Resources Development 33: 804-23. [CrossRef]

Welcher, Paul, and Ponnarong Prasertsri. 2019. Laos Rice Report MY2018-2019. Washington, DC: USDA Foreign Agricultural Service. World Bank. 2018. Lao PDR Economic Monitor Safeguarding Stability: An Ongoing Agenda. Washington, DC: World Bank. 